\title{
Impacts of Invasive Plants on Australian Rangelands
}

\section{By Jennifer Firn and Yvonne M. Buckley}

I n Australia, the spread and dominance of non-native plant species has been identified as a serious threat to rangeland biodiversity and ecosystem functioning. Rangelands extend over 70\% of Australia's land mass or more than 6 million $\mathrm{km}^{2} .^{1,2}$ These rangelands consist of a diverse set of ecosystems including grasslands, shrub-lands, and woodlands spanning numerous climatic zones, ranging from arid to mesic. Because of the high economic, social, and environmental values, sustainable management of these vast landscapes is critical for Australia's future. More than 2 million people live in these areas and major industries are ranching, mining, and tourism. In terms of biodiversity values, 53 of 85 of Australia's biogeographical regions and 5 of 15 identified biodiversity hotspots are found in rangelands. ${ }^{2}$

Many of the exotic invasive species within rangelands were intentionally introduced for pasture improvement, soil stabilization, and ornamental purposes. In the Australian National Weeds Strategy, 20 weeds have been listed as having impacts of national significance, with eight of these occupying rangelands. ${ }^{3}$ This is not, however, a comprehensive list; many more invasive species are distributed widely and are present at high densities across the country. A recent study found 622 exotic plant species present within Australian rangelands, with 160 of these identified as threats to biodiversity. ${ }^{2}$

In this article, we summarize the scientific evidence of the impacts invasive plants species have on Australian rangeland biodiversity and ecosystem functioning. We discuss four classes of impacts: 1) biodiversity, 2) hydrology, 3) fire regimes, and 4) nutrient cycling. These impacts were chosen because of the significant function each plays in the immediate, short-term, and long-term resilience of rangelands to climate fluctuations. To do this, we provide a general overview of the existing evidence on these impacts from a Web of Science ${ }^{\circledR}$ literature search (a multidisciplinary search engine provided by Thomson Reuters that allows access to the contents of more than 10,000 journals and over 110,000 conference proceedings). We then summarize the broad trends and briefly describe key examples of each impact. We use this evidence to recommend future research directions to improve the efficacy of control efforts in rangelands.

\section{Evidence that Invasive Plant Species Alter Biodiversity}

There is considerable evidence that invasive plant species negatively impact biodiversity within Australian rangelands. ${ }^{2}$ Evidence of an impact on biodiversity is described as the capacity of the invasive to form dense populations. These dense populations result in changes to the composition and structure of the communities they inhabit. The mechanisms that drive these changes, however, are more challenging to identify. The dominance of an invasive plant species could be driven by its competitive superiority for light, nutrients and/or water, or by disturbance(s) that asymmetrically affect native species over the invasive $e^{4}$, including the modification of ecological processes by the invader. ${ }^{3}$

A study by Martin et al. ${ }^{2}$ identified plant species that threaten rangeland biodiversity, using published and expert knowledge. To summarize this information, we grouped these species into two broad categories, growth form (i.e., shrubs/trees, grasses, forbs, and vines) and climatic region (i.e., semiarid/arid: $<350 \mathrm{~mm}$ rainfall per year, and mesic: $>350 \mathrm{~mm}$ rainfall per year; Table 1; see supplementary material [available at www.srmjournals.org] for species names covered by Table 1). In the semiarid/arid and mesic rangelands, shrubs and trees were the most numerous growth form, followed by grasses and then forbs. The conversion of grasslands to dense monocultures of trees and shrubs also has a high economic and social impact by reducing fodder, inhibiting the movement of livestock, and increasing the difficulty in rounding up stock for landholders. ${ }^{3}$

In the mesic rangelands of the Northern territory, mimosa (Mimosa pigra), a perennial leguminous shrub, is estimated to cover more than $800 \mathrm{~km}^{2}$ of floodplain regions previously occupied by native sedges and other herbaceous species. Mimosa forms dense monocultural thickets that change the structure of these sedge communities. ${ }^{5}$ This changed structure shades out native herbaceous plants and reduces the food, shelter, and nesting sites available for native fauna. ${ }^{3}$ In the semiarid/arid rangelands, the exotic tree Tamarisk (Tamarix aphylla) forms dense monocultural thickets previously dominated by more open, native, River red gum (Eucalytpus camaldulensis) forests along active river systems such as the Finke River. ${ }^{6}$ This has also resulted in a decrease in native flora and fauna diversity. ${ }^{6}$ 
Table 1. Summary of the limited evidence currently available on the impact of non-native plant species on biodiversity and ecosystem functions such as nutrient cycling, hydrology, and fire regimes

\begin{tabular}{|l|c|c|c|c|c|c|c|c|c|}
\hline & \multicolumn{4}{|c|}{ Arid/Semiarid } & \multicolumn{4}{c|}{ Mesic } \\
\cline { 2 - 10 } Impact & Shrubs/Trees & Grasses & Forbs & Vines & Shrubs/Trees & Grasses & Forbs & Vines \\
\hline Biodiversity & 24 & 13 & 15 & 2 & 36 & 22 & 18 \\
\hline Nutrient cycling & 0 & 0 & 0 & 0 & 1 & 1 & 0 \\
\hline Hydrology & 1 & 0 & 0 & 0 & 0 & 1 & 0 \\
\hline Fire regime & 0 & 1 & 0 & 1 & 2 & 2 & 0 \\
\hline
\end{tabular}

Note: The species have been organized into broad growth forms and climatic regions (categorized as dry and wet rangeland areas of Australia). Table 1 in supplementary material (available at www.srmjournals.org) lists the names of each of the species and more references.

\section{Evidence that Invasive Plant Species Alter Hydrology}

Few studies have investigated the hydrological impact of invasive plant species within rangelands. This is surprising considering the high variability of rainfall across rangelands and given the severity of changes predicted with climate change (Table 1; Table 2 supplementary material). This is also surprising considering the high populations of invasive species along riparian areas within Australian rangelands, particularly within arid and semiarid regions. ${ }^{3}$

In the mesic rangelands, Gamba grass (Andropogon gayanus), a tall, perennial grass, was originally introduced for pasture improvement, but has spread over large tracts of land. It is estimated to cover more than $15,000 \mathrm{~km}^{2}$ within the Northern Territory. Based on habitat suitability, it is predicted to be capable of doubling this range. ${ }^{7}$ When compared to pastures dominated by native perennial grasses, Gamba grass has been found to use three times the amount of water and to reduce the amount of water available through the soil profile. ${ }^{8}$ This high level of water use by Gamba grass could provide it with a competitive advantage over native grasses. The dominance of this species across large tracts of land, coupled with its high water use, could also reduce stream flow or result in earlier cessations of intermittent flows. ${ }^{8}$

In the arid rangelands, evidence suggests that Tamarisk is highly efficient at using soil moisture available at only very low levels because it is a poikilohydric species-it utilizes soil moisture in proportion to the amount available. Tamarisk is also highly salt tolerant. ${ }^{6}$ Evidence shows, however, that the habitats that this species dominates have experienced changes in hydrology including reduced occurrence of flooding and changes in the depth of the water table. This suggests that Tamarisk may dominate because of these hydrological changes rather than causing them. ${ }^{6}$

\section{Evidence That Invasive Plant Species Alter Fire Regimes}

Dominance by non-native plant species is altering the natural fire regimens of Australian rangelands. In general, the intensity and frequency of fire is increased by fastgrowing non-native grasses and decreased by non-native shrubs. Fire is a key driver of species diversity, nutrient cycling, and vegetation dynamics within Australian landscapes. Many species are adapted to fire, relying on heat and smoke as cues for germination. Dominance by a non-native plant species can change the characteristics of the fuel present, including its amount, distribution, continuity and curing time. This in turn alters fire intensity and frequency. These changes have profound implications for biodiversity and community structure. ${ }^{3}$ However, a considerable amount of anecdotal information exists concerning the effect of invasive plant species on fire regimes, and there is little data that quantitatively describes their impact. We found only six studies that measured impacts of invasive plant species on fire; most of this research has been conducted in the mesic rangelands (Table 1; Table 2 supplementary material).

There is evidence that high density stands of invasive shrub species, like mimosa and prickly acacia (Acacia nilotica), suppress fire in the mesic rangelands. The dominance of invasive grass species such as Gamba grass over large tracts of land has increased the intensity and frequency of fires. ${ }^{9}$ Fire intensity has been found to increase eight-fold in comparison to that in native grass communities. Gamba grass is a tall, highly productive grass species that produces 11 times more biomass than native perennial grasses even when burned annually. ${ }^{9}$

The perennial grass Buffel grass (Cenchrus ciliaris) is a valuable pasture species for livestock in arid and semiarid rangelands. Although it is not a declared weed, its spread within these regions is of great concern because of not only its impact on native biodiversity, but also its effects on natural fire regimes. ${ }^{3}$ Buffel grass produces a high-standing biomass that cures later in the year than that of native perennial grasses. There is strong evidence that these changes are resulting in more frequent and intense late-season fires. ${ }^{3,2}$

\section{Evidence That Invasive Plant Species Alter Nutrient Cycling}

Few studies have specifically examined the impact invasive plant species have on nutrient cycling (Table 1; Table 2 
supplementary material). As with hydrology, this is surprising considering the paucity of certain nutrients in some Australian soils and the key functional role nutrients play in community assembly, ecosystem processes, and livestock production.

There is evidence that dominance by Gamba grass alters nutrient cycling. ${ }^{7}$ A study by Rossiter-Rachor et al. found that, after a moderately intense fire, savannahs dominated by Gamba grass experienced a net loss of $20 \mathrm{~kg} / \mathrm{ha} /$ year of nitrogen. ${ }^{7}$ This is a $40 \%$ greater nitrogen loss than when savannahs dominated by native grasses are burned. Because dominance by Gamba grass also increases the intensity of fire $^{9}$, significant reductions in local soil nitrogen pools are predicted. In contrast, these more frequent and intense fires with increased nutrients in the resultant smoke plumes are predicted to increase nutrient levels at the regional scale. ${ }^{7}$ There are several invasive leguminous shrub species in Australian rangelands, e.g., Mimosa pigra (mesic), Acacia catechu (mesic), Acacia currasavica (mesic and semiarid), Acacia karroo (mesic and semiarid), Acacia nilotica (mesic), Senna occidentalis (mesic and arid/semiarid), Senna obtusifolia (mesic), and Senna tora (mesic). Because of symbiotic relationships with bacteria in root nodules, legume species are able to fix nitrogen from the atmosphere. Although little research has been conducted, these species have the potential to alter nutrient cycling in areas where they dominate, particularly in ecosystems where legume species were not previously present. There is some evidence that nitrogen fixation by mimosa can increase soil fertility and does act to redistribute nutrients from the lower levels of the soil profile toward the surface..$^{10}$

Invasive plant species are more abundant in areas where fertility has increased due to runoff and anthropogenic disturbances. ${ }^{3}$ As with impacts on hydrology, this increased fertility might open up an opportunity for changes in species composition, which may include non-natives. There is little evidence available in the scientific literature on how nutrient cycling is altered once novel communities assemble, including ones dominated by invasive plants.

\section{Understanding Impacts on Ecosystem Functions to Improve Control Efforts}

To date, ecological research into the impacts of invasive plant species within Australian rangelands has focused on the density and distribution of individual species and their impacts on the overall community structure. ${ }^{2,3}$ With the exception of a few species such as Gamba grass and mimosa, both found in the mesic rangelands, we know little of how the new invader-dominated systems function. Of the few studies available, all have been conducted on grasses and woody species. We found no research that quantifies the impact of forb species on ecosystem functioning.

This represents a significant short-fall in our knowledge, as understanding the impacts of an invasive plant species can help improve the efficacy of management efforts. For example, if an invasive plant species is having a negative impact on ecosystem functioning, then management efforts should target the species directly to manage its impact and return the desired function to the system. If the invasive plant species is instead a symptom of other perturbations, targeting the invader for control may not be effective. In this case, the ecosystem may have changed to an extent where native species are no longer able to recruit and survive under the new conditions. ${ }^{11} \mathrm{~A}$ better strategy may be to invest in reclaiming or rehabilitating the dynamics of an ecosystem. This requires, however, an understanding of how the new invader-dominated ecosystems function and if known, how the previous native-dominated ecosystems functioned. If historical function is not known, then clearly defined management objectives on how future ecosystems should function are necessary. ${ }^{11}$ Otherwise, investing time, effort, and money in the application of generic control strategies to reduce the density of the invader, with little consideration for the characteristics of the ecosystem being managed or invader impact, are likely to be ineffective ${ }^{12}$ and to lead to further degradation.

Evidence of the impact an invasive species has on key ecosystem functions will also help set management priorities between species. Given the limited resources available, it is a tremendous challenge to decide which of the many invasive species present in Australian rangelands should be targeted. It may be that some invasive plant species function in a similar manner to the previous community and therefore have little impact or may be the only species capable of surviving altered resource conditions. These species may be a lower priority for management from a regional perspective, but they may remain a priority at local levels.

The most common control strategy for an invasive plant species is to remove or kill the species. This represents a generic approach to invasive species management, because regardless of the species and the functioning of the ecosystem it dominates, the same control measures are applied. In the case where the invasive plant species is a symptom of other perturbations, generic control strategies are likely to prove ineffectual and simply targeting the weed for local removal could lead to the re-establishment of the same invader or another. ${ }^{4}$ Instead, what is needed is an approach that takes into consideration the new dynamics of the novel invader-dominated ecosystem. ${ }^{11}$

There is an urgent need for restoration efforts to be re-focused on the present and the future, not just the past. Invasive species are abundant and widely distributed in our rangelands. It is essential now that the dynamics of the new ecosystems including how they function be understood, in order to reduce the impacts of the invaders. To effectively manage the well-established and broad distribution of many of our invasive species, we need a new set of strategies to better manage the increasing number of invader-dominated novel ecosystems. ${ }^{11}$ For example, in a recent study by Firn 
et al. ${ }^{13}$ cattle grazing and fertilizer (low application rate of $2 \mathrm{~kg} / \mathrm{ha}$ ) were found to be the most effective control strategies for reducing the abundance of an invasive perennial grass species, African lovegrass (Eragrostis curvula). This was also found to be the most effective strategy for increasing the abundance of native grasses and preventing the secondary invasion of an exotic forb such as Mayne's pest or Verbena tenuisecta. The more traditional control strategy of applying herbicides killed African lovegrass but resulted in an increased abundance of Mayne's pest. Initially, this combination of control strategies appears at odds with restoration efforts because ungulate grazing and nutrient addition have been associated with the degradation of grassland communities. In this example, the invasive grass has a low palatability, but can increase in palatability with a small increase in soil nutrients. Therefore, nutrient addition shifted the grazing pressure towards the invasive grass and relieved pressure on the more desirable native grasses. This is an example of how knowing the characteristics of the undesirable species and the dynamics of the changed ecosystem can aid in the design of more effective control strategies.

Making the effort to understand the dynamics of the new invader-dominated ecosystem is a more difficult approach to implement than the current generic approach because, in the short-term, it requires deeper knowledge of the impacts of invaders and may also require more effort, money, and resources. In the long term, however, it has the potential to lead to more effective management strategies for the rehabilitation and possible restoration of the environmental and economic functions of rangelands.

\section{Acknowledgments}

The authors wish to thank Tony Grice, Tara Martin, and two anonymous reviewers for helpful comments on an earlier draft of this manuscript. Funding was provided by an Australian Research Council Discovery grant scheme to Buckley (DP0771387).

\section{References}

1. Grice, A. C. 2004. Weeds and the monitoring of biodiversity in Australian rangelands. Austral Ecology 29:51-58.

2. Martin, T. G., S. Campbell, and S. Grounds. 2006. Weeds of Australian rangelands. Rangeland Journal 28:3-26.

3. Grice, A. C. 2006. The impacts of invasive plant species on the biodiversity of Australian rangelands. Rangeland Journal 28: 27-35.

4. Buckley, Y. M., B. M. Bolker, And M. Rees. 2007. Disturbance, invasion and re-invasion: managing the weed-shaped hole in disturbed ecosystems. Ecology Letters 10:809-817.
5. Firn, J., T. Rout, H. P. Possingham, and Y. M. Buckley. 2008. Managing beyond the invader: manipulating disturbance of natives simplifies control efforts. Journal of Applied Ecology 45:1143-1151.

6. Griffin, G. F., D. M. S. Smith, S. R. Morton, G. E. Allan, K. A. Masters, and N. Preece. 1989. Status and implications of the invasion of Tamarisk (Tamarix-aphylla) on the Finke River, Northern Territory, Australia. Journal of Environmental Management 29:297-315.

7. Rossiter-Rachor, N. A., S. A. Setterfield, M. M. Douglas, L. B. Hutley, and G. D. Соок. 2008. Andropogon gayanus (Gamba grass) invasion increases fire-mediated nitrogen losses in the tropical savannas of Northern Australia. Ecosystems 11:77-88.

8. Douglas, M. M., and S. A. Setterfield. 2005. Impacts of exotic tropical grasses: lessons from Gamba grass in the Northern Territory. In: W. D. Vogler [ED.]. 8th Queensland weed symposium: weed management-making a difference. Townsville, Australia: The Weed Society of Queensland. p. 69-73.

9. Rossiter, N. A., S. A. Setterfield, M. M. Douglas, and L. A. Hutley. 2003. Testing the grass-fire cycle: alien grass invasion in the tropical savannas of northern Australian. Diversity and Distribution 9:169-176.

10. Miller, I. L. 2004. Uses for Mimosa pigra. In: M. H. Julien, G. Flanagan, T. Heard, B. Hennecke, Q. Paynter, and C. Wilson [EDS.]. 3rd international symposium on the management of Mimosa pigra. Darwin, Australia: Charles Darwin University. p. 63-67.

11. Нobbs, R. J., S. Arico, J. Aronson, J. S. Baron, P. Bridgewater, V. A. Cramer, P. R. Epstein, J. J. Ewel, C. A. Klink, A. E. Lugo, D. Norton, D. Ojima, D. M. Richardson, E. W. Sanderson, F. Valladares, M. Vila, R. Zamora, And M. Zobel. 2006. Novel ecosystems: theoretical and management aspects of the new ecological world order. Global Ecology and Biogeography 15:1-7.

12. Yокомizo, H., Н. P. Possingham, M. B. Thomas, and Y. M. Buckley. 2009. Managing the impact of invasive species: the value of knowing the density-impact curve. Ecological Applications 19:376-386.

13. Firn, J., A. P. N. House, and Y. M. Buckley. 2009. Alternative states models provide an effective framework for invasive species control. Journal of Applied Ecology doi:10.1111/j.13652664.2009.01741.x.

Authors are Postdoctoral Fellow at CSIRO Sustainable Ecosystems, St Lucia, QLD 4067, Australia, jennifer.firn@csiro.au (Firn); and Visiting Scientist at CSIRO Sustainable Ecosystem and Australian Research Fellow/Senior Lecturer at the University of Queensland, School of Biological Sciences, Brisbane, QLD 4072, Australia (Buckley). 